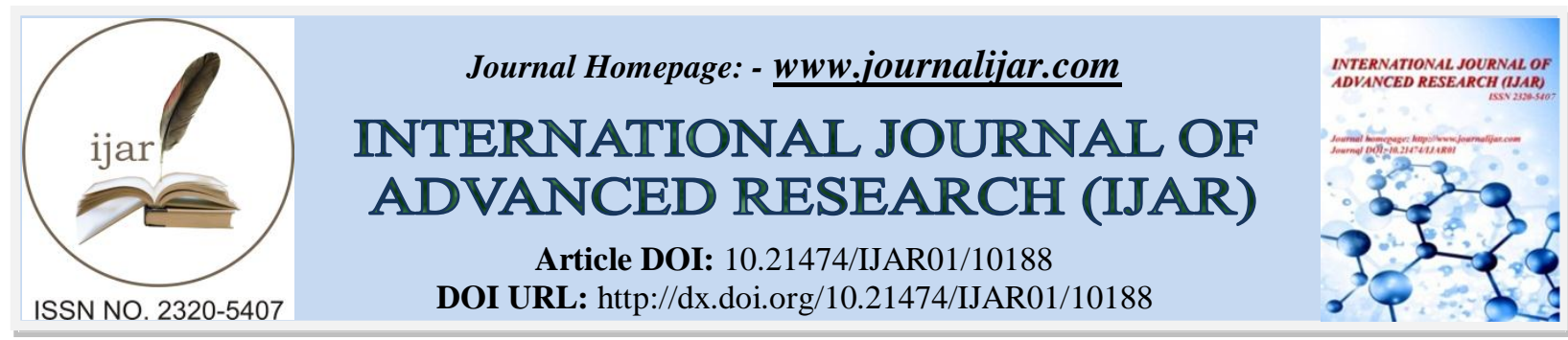

RESEARCH ARTICLE

\title{
FORECASTING CRYPTOCURRENCY PRICE MOVEMENT USING MOVING AVERAGE METHOD: A CASE STUDY OF BITCOIN CASH
}

\author{
Nashirah Abu Bakar ${ }^{1}$, Sofian Rosbi ${ }^{2}$ and Kiyotaka Uzaki ${ }^{3}$ \\ 1. Islamic Business School, College of Business, Universiti Utara Malaysia, Kedah, Malaysia. \\ 2. School of Mechatronic Engineering, Universiti Malaysia Perlis, Malaysia. \\ 3. Faculty of Economics, Oita University, Japan.
}

\section{Manuscript Info}

\section{Manuscript History}

Received: 08 October 2019

Final Accepted: 10 November 2019

Published: December 2019

Key words: -

Forecasting, Moving Average Method,

Cryptocurrency, Investment

\begin{abstract}
The aim of this study is to develop forecasting cryptocurrency price movement using moving average. The cryptocurreny that selected in this study is Bitcoin Cash. The observation periods involved in this study are starting from $1^{\text {st }}$ October 2019 until $20^{\text {th }}$ December 2019. The price of Bitcoin Cash are collected from https://www.coindesk.com. The moving average forecasting method implemented using 2-days, 3days, 4-days and 7-days calculation. The value of mean absolute error percentage for 2-days moving average forecasting method is $3.1 \%$. The significant of this study is it can help investors to determine the price movement of cryptocurrency in selecting best option for investment portfolio.
\end{abstract}

Copy Right, IJAR, 2019,. All rights reserved.

\section{Introduction:-}

Cryptocurrency have been used widely as a store of value that is non-physical of which no banknotes and coins exist (Ram, 2019; Narayanan et al., 2016; Ram et al., 2016; Antonopoulos, 2017). Cryptocurrency is defining as a peer to peer electronic cash that can be described as online money sent from one person to another without the need for a trusted third-party (Nakamoto, 2019). The transaction of cryptocurrency only can be performed via electronic typically allowing for instantaneous transactions and borderless transfer of ownership (Abu Bakar, et al., 2017a).

The system for cryptocurreny transaction is known as blockchain. The blockchain is blocks of transaction history that shared publicly using secured cryptography. Each block contains the previous transaction information, timestamp and new transaction data in secured cryptographic hash programming language (Abu Bakar and Rosbi, 2018bc).

In July 2019, the price of Bitcoin cash has risen above USD $\$ 470$ and attract the world's largest user to discuss a topic of Bitcoin cash among a variety of disciplines such as economics, computer science and payments to public policy, information systems, and policy maker. Bitcoin cash also being taken quite seriously by academision worldwide. The advantages of Bitcoin cash are fast, reliable, low fees, simple, stable and secure. Therefore, it is important to examine the Bitcoin cash cryptocurrency. Thus, this study investigates the price movement of Bitcoin cash using moving average method.

Corresponding Author: - Nashirah Abu Bakar.

Address: - Islamic Business School, College of Business, Universiti Utara Malaysia, Kedah, Malaysia. 
Bitcoin cash is a cryptocurrency created in August 2017. Bitcoin cash increases the size of blocks, allowing more transactions to be processed. The cryptocurrency underwent another fork in November 2018 and split into Bitcoin Cash ABC and Bitcoin Cash SV (Satoshi Vision). Now, Bitcoin Cash seeing an increase in demand and acceptance by the users. Many methods can be used in forecasting methods. Abu Bakar and Rosbi (2019c) used Modern Portfolio Theory in prediction shares price of companies listed on the Malaysian Stock Market. Abu Bakar and Rosbi (2019d) combination of Modern Portfolio Theory and genetic algorithm optimization approach for reducing investment portfolio risk.

\section{Literature review:-}

Over the last few years, a wide range of digital currencies, such as BitCoin, Ethereum, Litecoin and Ripple have emerged (Abu Bakar and Rosbi, 2019e). Cryptocurrency has no physical form and exists only in the network. Bitcoin also has no intrinsic value in that it is not redeemable for another commodity, namely gold (Abu Bakar, et al., 2017a). Although several types of cryptocurrency are in operation in the current digital economy, the most prevalent is the Bitcoin, which was launched formally in 2009 (Nakamoto, 2009; Majumder, et al., 2019). Ram (2019) finds that the Bitcoin represents a distinct alternative investment and asset class. Using Sharpe Ratios shown that the Bitcoin provides risk-adjusted returns over and above most asset classes.

Abu Bakar and Rosbi (2017f) validates the normality distribution of data using graphical and numerical method indicates that the growth of Bitcoin exchange rate in moving towards non-equilibrium point. In the other analysis by Abu Bakar and Rosbi (2017g) found that the high value of volatility for Bitcoin cryptocurrency indicates that the investment is categorical as high risk investment. Buchholz, et al., (2012) found that before the peak of the bubble, volatility had a statistically significant positive effect on price of Bitcoin. Miglietti, et al., (2019) indicate that the Litecoin is more volatile than Bitcoin. Vardar and Aydogan (2019) reveal the existence of the positive unilateral return spillovers from the bond market to Bitcoin market. Regarding the results of shock and volatility spillovers, there exists strong evidence of bidirectional cross-market shock and volatility spillover effects between Bitcoin and all other financial asset classes, except US Dollar exchange rate. Study regarding correlation of Bitcoin with market index indicated that Bitcoin has low correlation with the market index (Alfieri, et al., 2019). Abu Bakar and Rosbi (2018h) evaluate the correlation of dynamic movement of exchange rate between Bitcoin and Ethereum indicates the correlation factor between Bitcoin and Ethereum is 0.653 .

Kostika and Laopodis (2019) examined are Bitcoin, Dash, Ethereum, Monero, Stellar and XRP. The data were collected on major exchange rates with respect to the US dollar, namely, the euro, British pound, Japanese yen and Chinese Yuan. The results show that despite sharing some common characteristics, the cryptocurrencies do not reveal any short- and long-term stochastic trends with exchange rates and/or equity returns. The dynamics of each cryptocurrency with the Chinese Yuan appears to be more turbulent than the other exchange rates. Ciaian, et al., (2016) found that Bitcoin market fundamentals and Bitcoin's attractiveness for investors have a significant impact on Bitcoin price.

Karalevicius, et al. (2018) identified that interaction between media sentiment and the Bitcoin price exists, and that there is a tendency for investors to overreact on news in a short period of time. Abu Bakar and Rosbi (2018i) develop investment portfolio with diversifications using two different assets namely, cryptocurreny (Bitcoin) and stock price (Petronas Gas Berhad) as the combination indeveloping investment portfolio. The results indicated that mean return for Bitcoin is $9.890 \%$. Meanwhile, the mean return for stock price of Petronas Gas Berhad is $-0.496 \%$. The value of correlation is between two assets is - 0.372 . Speculative in investment behavior of Bitcoin is driven by strong impulse and weak self-control, leading to negative consequences (Ryu and Ko, 2019).

\section{Methodology:-}

This study selected daily price of Bitcoin Cash data from https://www.coindesk.com. The selected observation started from $1^{\text {st }}$ October 2019 until $20^{\text {th }}$ December 2019 with 80 daily observations. This study calculated the percentages of changes using Equation (1) as follows:

$$
P C_{i}(\%)=\left(\frac{P_{i}-P_{i-1}}{P_{i-1}}\right) \times 100 \%
$$

In Equation (1), the parameters are described as below:

$P C_{i}(\%)$ : Percentage of price changes for Bitcoin Cash at observation period i, 
$P_{i-1}$ : Price of Bitcoin cash at observation period i-1, and

$P_{i}$ : Price of Bitcoin cash at observation period i.

Then, this study calculated moving average prediction method using Equation (2) until (5).

$$
\begin{aligned}
& M A(2)_{i}=\frac{P_{i-1}+P_{i-2}}{2} \\
& \operatorname{MA}(3)_{i}=\frac{P_{i-1}+P_{i-2}+P_{i-3}}{3} \\
& M A(4)_{i}=\frac{P_{i-1}+P_{i-2}+P_{i-3}+P_{i-4}}{4} \\
& M A(7)_{i}=\frac{P_{i-1}+P_{i-2}+P_{i-3}+P_{i-4}+P_{i-5}+P_{i-6}+P_{i-7}}{7}
\end{aligned}
$$

Next, in evaluating the effectiveness of prediction methods, absolute percentage error is calculated with comparison to real data as shown in Equation (6).

$A P E_{i}=\left|\frac{V_{A}-V_{E}}{V_{E}}\right| \times 100 \%$

$A P E_{i}:$ Absolute percentage error for observation period $\mathrm{i}$,

$V_{A}$ : value of approximation using prediction method

$V_{E}$ : exact value of Bitcoin Cash.

Then, this study calculated mean absolute percentage error using Equation (7) for $\mathrm{n}$ observation periods.

$$
M A P E=\frac{\sum_{i=1}^{n}\left(\left|\frac{V_{A}-V_{E}}{V_{E}}\right| \times 100 \%\right)}{n}
$$

\section{Result and Discussion:-}

This study evaluated forecasting method for predicting price of a cryptocurrency namely Bitcoin Cash. Figure 1 shows the dynamic movement of price for Bitcoin Cash. The number of observation is 80 days. The observation started on $1^{\text {st }}$ October 2019 until $20^{\text {th }}$ December 2019. The value of Bitcoin Cash on $1^{\text {st }}$ October 2019 is USD 226.1 for each unit. The value of Bitcoin Cash on $20^{\text {th }}$ December 2019 is USD 186.5 for each unit. The maximum value of Bitcoin Cash during observation period is on $7^{\text {th }}$ November $2019\left(39^{\text {th }}\right.$ observation data $)$ with value of USD 303.3 for each unit. Meanwhile, the minimum value of Bitcoin Cash during observation period is on $18^{\text {th }}$ December 2019 ( $78^{\text {th }}$ observation data) with value of USD 175.4 for each unit.

Next, this study performed calculation for percentage of changes for price of Bitcoin Cash. Figure 2 indicates the dynamic movement for price changes of Bitcoin Cash. The maximum value of changes is $16.07 \%$ on $26^{\text {th }}$ October 2019 ( $25^{\text {th }}$ observation data). The minimum value is $-11.7 \%$ for changes of Bitcon Cash on $18^{\text {th }}$ December 2019 ( $78^{\text {th }}$ observation data).

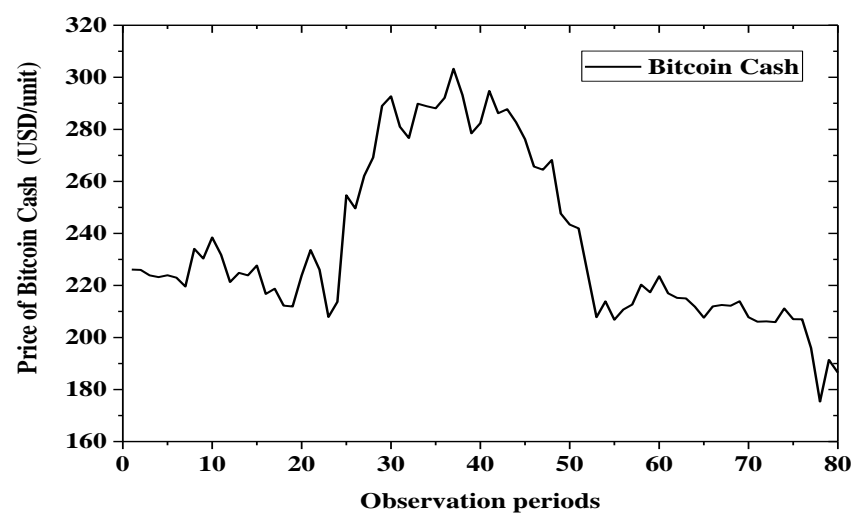

Figure 1:- Dynamic movement of price for Bitcoin Cash. 


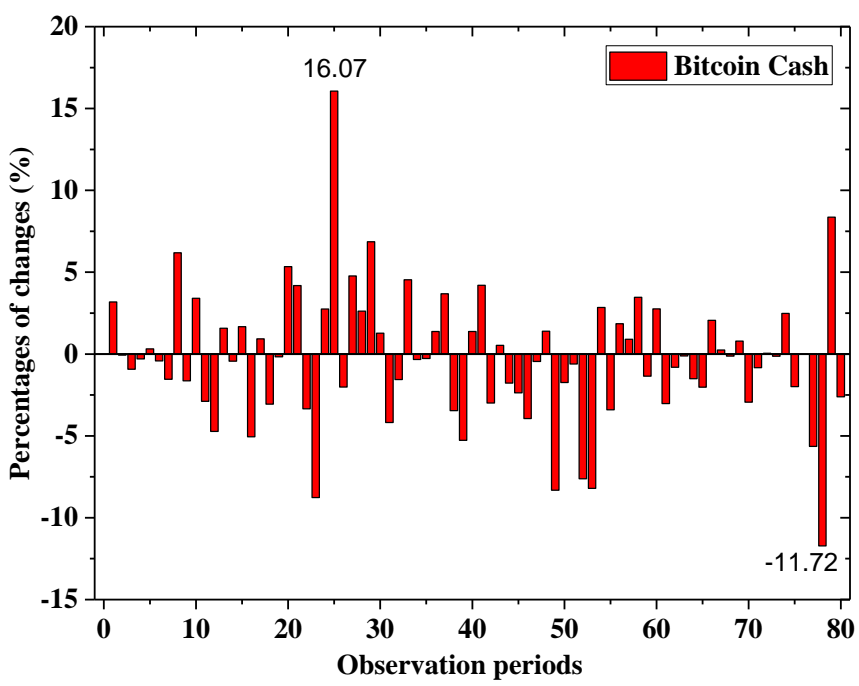

Figure 2:- Percentages of price changes for Bitcoin Cash.

Next, this study evaluated forecasting method using 2-days moving average, 3-days moving average, 4-days moving average and 7-days moving average. Figure 3 shows comparion of real data with forecasting moving average. Figure 3 shows if the changes of price is large, 2-days moving average methods indicates more valid result with close to real value of Bitcoin Cash. However, in range of changes is small, the differences between prediction methods are not significant.

Next, in validating the finding in Figure 3, this study performed calculation of absolute error percentages for comparison between real value and prediction value. Figure 4 validated the findings that 2 -days moving average prediction methods in better than other three prediction methods with lowest absolute error percentage. The 2-days moving is more sensitive to recent changes in latest data. Therefore, the 2-days moving average shows less error with actual data during all of observations.

Table 1 shows mean absolute error percentage for four types of prediction method using moving average. Figure 4 and Table 1 show an agreement that 2-days moving average method is the better prediction method with lowest mean absolute error percentage which is $3.109 \%$.

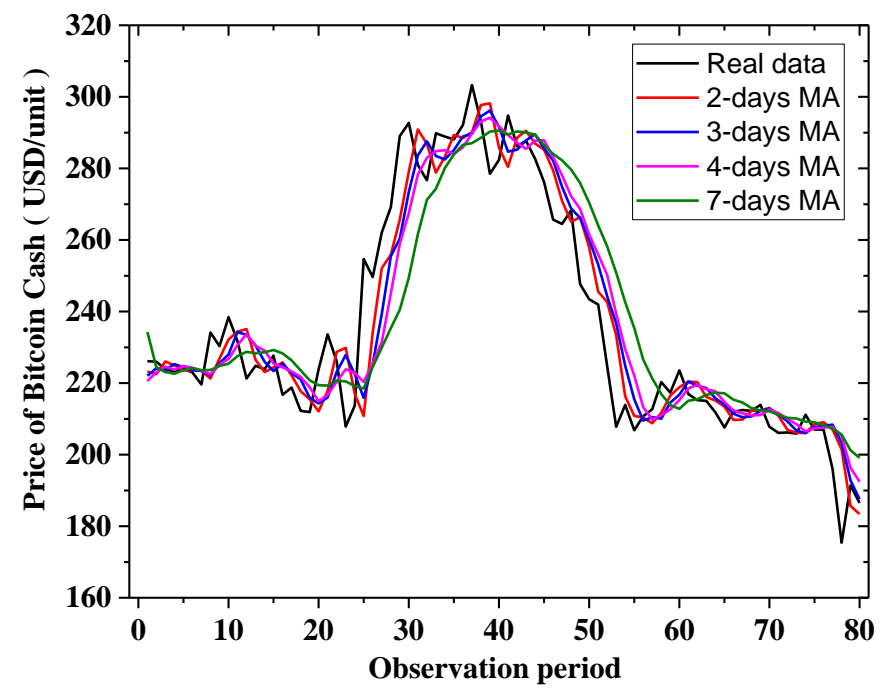

Figure 3:- Comparison of real data with four prediction methods. 


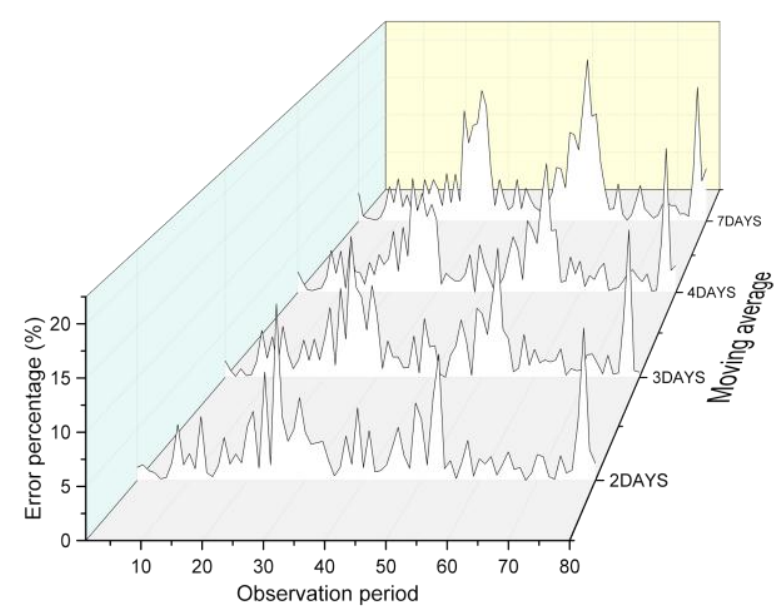

Figure 4:- Absolute error percentage for four prediction methods.

Table 1:- Mean absolute error percentage for four prediction methods.

\begin{tabular}{|l|l|}
\hline Forecasting method & Mean absolute error percentage (\%) \\
\hline 2-days Moving Average & $3.109 \%$ \\
\hline 3-days Moving Average & $3.464 \%$ \\
\hline 4-days Moving Average & $3.832 \%$ \\
\hline 7-days Moving Average & $4.786 \%$ \\
\hline
\end{tabular}

\section{Conclusion:-}

The main objective of this paper is to develop forecasting method for Bitcoin Cash using moving average method. The main findings of this study are as follow:

1. The value of Bitcoin Cash on $1^{\text {st }}$ October 2019 is USD 226.1 for each unit. The value of Bitcoin Cash on $20^{\text {th }}$ December 2019 is USD 186.5 for each unit. The maximum value of Bitcoin Cash during observation period is on $7^{\text {th }}$ November 2019 ( $39^{\text {th }}$ observation data) with value of USD 303.3 for each unit. Meanwhile, the minimum value of Bitcoin Cash during observation period is on $18^{\text {th }}$ December 2019 ( $78^{\text {th }}$ observation data) with value of USD 175.4 for each unit.

2. Comparison among prediction methods, 2-days moving average method is the better prediction method with lowest mean absolute error percentage for all observation periods.

\section{Acknowledgement:-}

The authors would like to thank Institute for Management and Business Research (IMBRe) of Universiti Utara Malaysia (UUM) for their financial support under research grant scheme "Case Study Research Grant" SO code number 14501 .

\section{References:-}

1. Abu Bakar, N., Rosbi, S. and Uzaki, K. (2017a). Cryptocurrency Framework Diagnostics from Islamic Finance Perspective: A New Insight of Bitcoin System Transaction. International Journal of Management Science and Business Administration, 4 (1), 19-28.

2. Abu Bakar, N. and Rosbi, S. (2018b). Robust Framework Diagnostics of Blockchain for Bitcoin Transaction System: A Technical Analysis from Islamic Financial Technology (i-FinTech) Perspective. International Journal of Business and Management, 2 (3), 22-29.

3. Abu Bakar, N. and Rosbi, S. (2019c). Robust Statistical Portfolio Investment in Modern Portfolio Theory: A Case Study of Two Stocks Combination in Kuala Lumpur Stock Exchange, International Journal of Engineering and Advanced Technology,

4. Abu Bakar, N. and Rosbi, S. (2019d). Robust Hybrid Optimization Method to Reduce Investment Portfolio Risk using Fusion of Modern Portfolio Theory and Genetic Algorithm. International Journal of Engineering and Advanced Technology 
5. Abu Bakar, N. and Rosbi, S. (2019e). Forecasting method for Ethereum cryptocurrency with autoregressive integrated moving average (ARIMA) model using high-frequency data. Revista Religacion, 4 (17), 9-20.

6. Abu Bakar, N. and Rosbi, S. (2017f). Identification of Non-Equilibrium Growth for Bitcoin Exchange rate: Mathematical Derivation Method in Islamic Financial Engineering. International Journal of Scientific Research and Management, 5 (12), 7772-7781.

7. Abu Bakar, N. and Rosbi, S. (2017g). High Volatility Detection Method Using Statistical Process Control for Cryptocurrency Exchange Rate: A Case Study of Bitcoin. The International Journal of Engineering and Science, 6(11), 39-48.

8. Abu Bakar, N. and Rosbi, S. (2018h). Statistical Diagnostics for Bivariate Correlation and Regression Analysis between Cryptocurrency Exchange Rates of Bitcoin and Ethereum. International Journal of Economics, Commerce and Management, VI (4), 455-465.

9. Abu Bakar, N. and Rosbi, S. (2018i). Diversification Diagnostics for Portfolio Investment Using Combination of Cryptocurrency and Stock Price. International Journal of Advanced Research, 6 (10), 1528-1539.

10. Alfieri, E., Burlacu, R. and Enjolras, G. (2019). On the nature and financial performance of bitcoin. Journal of Risk Finance, 20(2), 114-137.

11. Antonopoulos, A.M. (2017), Mastering Bitcoin, O’Reilly Media, Sebastopol, CA.

12. Buchholz, M., Delaney, J., Warren, J. and Parker, J. (2012). Bits and Bets, Information, Price Volatility, and Demand for BitCoin, Economics 312, available at: http:// www.bitcointrading.com/pdf/bitsandbets.pdf

13. Ciaian, P. Rajcaniova, M. and Kancs, D.A. (2016). The economics of BitCoin priceformation. Apply Economic, 48(19), 1799-1815.

14. Karalevicius, V., Degrande, N. and De Weerdt, J. (2018). Using sentiment analysis to predict interday Bitcoin price movements. Journal of Risk Finance, 19(1), 56-75.

15. Kostika, E. and Laopodis, N. (2019). Dynamic linkages among cryptocurrencies, exchange rates and global equity markets. Studies in Economics and Finance, 1-23.

16. Majumder, A., Routh, M. and Singha, D. (2019). A Conceptual Study on the Emergence of Cryptocurrency Economy and Its Nexus with Terrorism Financing. Das, R. (Ed.) The Impact of Global Terrorism on Economic and Political Development, Emerald Publishing Limited, pp. 125-138.

17. Miglietti, C., Kubosova, Z. and Skulanova, N. (2019). Bitcoin, Litecoin, and the Euro: an annualized volatility analysis. Studies in Economics and Finance, 1-14.

18. Nakamoto, S. (2009). Bitcoin: A peer-to-peer electronic cash system, Retrieved from http://www.bitcoin.org /bitcoin.pdf

19. Narayanan, A., Bonneu, J., Felten, E., Miller, A. and Goldfeder, S. (2016) Bitcoin and Cryptocurrency Technologies: A Comprehensive Introduction, Princeton University Press, Princeton.

20. Ram, A. (2019). Bitcoin as a new asset class. Meditari Accountancy Research, 27(1), 147-168.

21. Ram, A., Maroun, W. and Garnett, R. (2016). Accounting for the Bitcoin: accountability, neoliberalism and a correspondence analysis. Meditari Accountancy Research, 24(1), 2-35.

22. Ryu, H. and Ko, K. (2019). Understanding speculative investment behavior in the Bitcoin context from a dualsystems perspective. Industrial Management \& Data Systems, 119(7), 1431-1456.

23. Vardar, G. and Aydogan, B. (2019). Return and volatility spillovers between Bitcoin and other asset classes in Turkey: Evidence from VAR-BEKK-GARCH approach. EuroMed Journal of Business, 14(3), 209-220. 